\title{
Expression of CD44 Gene in Goat's Oocytes and Embryos
}

\section{AMINAFSHAR M. ${ }^{1}$, BAHRAMPOUR V. ${ }^{1 *}$, BAGIZADEH A. ${ }^{2}$, KASHAN N. Emam Jomeh ${ }^{1}$ and ABADI M.R. Mohamad ${ }^{3}$}

\author{
${ }^{1}$ Department of Animal Science and Science and Research Branch, Islamic Azad University, \\ Tehran, Iran. \\ ${ }^{2}$ Department of Gentic and Advanced Sciences University, Kerman, Iran. \\ ${ }^{3}$ Department of animal Science and Shahid Bahonar University, Kerman, Iran.
}

Article No.: 050614223

Type: Research

DOI: 10.15580/GJBS.2014.5.050614223

Submitted: 06/05/2014

Accepted: 29/05/2014

Published: 11/06/2014

${ }^{*}$ Corresponding Author

V. Bahrampour

E-mail: v_bahrampur@yahoo.com

Keywords:

Gene expression, Hemi nested PCR, Goat, Oocyte, Embryos
The CD44 family belongs to a larger group of hyaluronic acid-binding proteins and plays important roles in oocyte maturation, fertilization and preimplantational embryo development. We analyzed the CD44 receptor in goat oocytes and embryos. Immature oocytes $(N=90)$ were obtained from a local abattoir; mature oocytes $(N=40)$ and embryos $(N=25)$ were obtained by laparotomy from adult hair ewes submitted to ovarian stimulation treatment. The CD44 mRNA was detected by PCR, after reverse transcription, while proteins were located by indirect immunofluorescence, using anti-human CD44 monoclonal antibody. Human lymphocytes and immature bovine oocytes were used as positive and negative controls respectively. Assessment of the oocyte nuclear stages as well as classification of the embryonic Growth phase were made with Hoechst 33342 staining. Indirect immunofluorescence detected CD44 expression on the surface of mature oocytes and embryos; immature oocytes did not take up the stain. These findings were supported by the RT-PCR data, which showed no mRNA templates for CD44, in material from immature oocytes and cumulus cells. The CD44 amplicons were detected after a second hemi-nested PCR in mature oocytes and embryos. The finding of CD44 in mature oocytes and preimplantational embryos could reflect the expression profile of hyaluronic acid during terminal folliculogenesis and preimplantational embryo development in goats. 


\section{INTRODUCTION}

The communication between the oocyte and the granulosa cells surrounding is crucial for the acquisition of oocyte competence (Assidi et al., 2008). One way of oocyte and cumulus cells communication is characterized by the secretion of several growth factors such as glycosaminoglycans (GAGs), which play an important role in proliferation and differentiation of a variety of cell types (Jackson et al., 1991).

Among the GAGs, hyalurunic acid (HA) is a high molecular weight polysaccharide found in the extracellular matrix of most animal tissues and is one of the most abundant GAGs in the uterine, oviductal and follicular fluids in woman (Ohta et al., 2001), mouse (Sato et al., 1987), sow (Archibong et al., 1989), and cow (Lee and $A x$, 1984). During the process of ovulation, cumulus cells secrete HA (Salustri et al., 1990) that actively participates in processes of cytoskeletal modification, gap junction losses that accompany cumulus expansion in cumulus-oocyte complexes (COCs) and oocyte meiotic progression (Allworth and Albertini, 1993). The expansion of cumulus cells may be positively correlated to the ovulation, fertilization, and subsequent zygote development (Chen et al., 1993). The degree of cumulus cells expansion is often cited as a major indicator oocyte selection for in vitro fertilization protocols (Yokoo et al., 2010). It has also been demonstrated that HA delays death and prevents fragmentation of porcine oocytes (Sato et al., 1994; Tunjung et al., 2009) and plays a role in cell migration during the early embryonic development (Peterson et al., 1993). Moreover, HA added to the culture medium supports the development of 1- and 2-cell porcine embryos (Miyano et al., 1994) as well as improving in vitro bovine embryo development to the blastocyst stage (Furnus et al., 1998). HA mainly binds to CD44, which is a glycoprotein widely expressed on the surface of many mammalian cells. CD44 exists as multiple isoforms expressed in a specific manner for different cell types. These isoforms result from splicing and post-translational modifications, where they can be differently glycosylated (Kaya et al., 2001). Cell surface glycoprotein CD44 is present in mature oocytes and preimplantation embryos in some species of mammals such as in humans (Campbell et al., 1995), bovine (Furnus et al., 2003), porcine (Toyokawa et al., 2005), and mouse (Wheatley et al., 1993). Furthermore, CD44 was not detected in immature oocytes in porcine (Yokoo et al., 2007), bovine (Furnus et al., 2003), mice (Fulop et al., 1997), and humans (Campbell et al., 1995). These data indicate that CD44 is expressed during the maturation process suggesting its importance in this phase. It is reasonable to assume that HA profile is directly proportional to the amount of CD44 in somatic cells surrounding the growing oocyte.

\section{MATERIAL AND METHODS}

\section{Immature oocytes}

Thirty adult hair Goat ovaries were obtained from a local abattoir and transported in vivo matured oocyte five goats aging 3 to 6 years were used as mature oocyte donors. Estrus was synchronized with intravaginal sponge containing 50 mg medroxyprogesterone acetate inserted for 20 days. In addition, follicular development was stimulated by a gonadotrophin treatment consisting in a multi-injection regime of a total $150 \mathrm{mg} \mathrm{pFSH}$ administered intramuscularly initially $48 \mathrm{~h}$ before removing the sponge, in decreasing doses twice daily for three days. Estrus was detected at $24 \mathrm{~h}$ after sponge removal using a teaser. The oocytes were collected at $96 \mathrm{~h}$ after sponge removal by laparotomy followed by oviductal flushing. The oviduct was flushed retrogradely with 15-20 mL DMPBS and the recovered structures were evaluated under a stereomicroscope at 10 to 50X magnification. Matured oocytes were identified by the presence of the first polar body and expanded cumulus cells. The structures were stripped mechanically by successive pipetting and the denuded oocytes were immediately used for indirect immunofluorescence or frozen $\left(-80^{\circ} \mathrm{C}\right)$ until its use for PCR.

\section{Mature oocytes}

Three hair goats aging 3 to 6 years were used as mature oocyte donors. Estrus was synchronized Injections were carried out for $14 \mathrm{~h}$ before sponge removal. In addition, follicular development was stimulated by a gonadotrophin treatment consisting in a multi-injection regime of a total $150 \mathrm{mg} \mathrm{pFSH}$ (Folltropin-V, Vetrepharm, Ontario, Canada) administered intramuscularly initially $48 \mathrm{~h}$ before removing the sponge, in decreasing doses twice daily for four days. The oocytes were collected at $100 \mathrm{~h}$ after sponge removal by Removing the uterus followed by oviductal lushing. The structures were stripped mechanically by successive pipetting and the denuded oocytes were immediately used for indirect immunoluorescence or frozen $\left(-80^{\circ} \mathrm{C}\right)$ until its use for nested PCR.

\section{Embryo production}

Five goats aging 3 to 6 years were submitted to the same hormonal treatment as previously described. Additionally, females were mated at the beginning of estrus and $24 \mathrm{~h}$ afterward, using rams of proven fertility Embryo recovery was performed by laparotomy six days after thefirst mating.

Respectively, Obtained $(\mathrm{N}=90)$ cumulus cells obtained from immature COCs $(\mathrm{N}=70)$, and embryos $(\mathrm{N}=40)$ using the RNeasy micro kit (kia gene) according to manufacturer instructions. Briefly, $75 \mu \mathrm{L}$ lysis buffer was added to each frozen sample and the lysate was diluted $1: 1$ with $70 \%$ ethanol and transferred to a spin column. Genomic DNA was degraded using RNase-free, DNase for $15 \mathrm{~min}$ at room temperature. After three washes, the RNA was eluted 
with $10 \mu \mathrm{L}$ RNase-free water.

\section{PCR}

The cDNA amplification was conducted with two rounds of hemi-nested using PCR primers to increase the specificity and yield of the PCR product. The total 20- $\mu \mathrm{L}$ PCR product contained $2 \mu \mathrm{L}$ reverse-transcribed cDNA, 0.5 IU GoTaq DNA polymerase (Promega), 0.2 $\mathrm{mM}$ of each dNTP, $2 \mathrm{mM} \mathrm{MgCl} 2$ and $0.2 \mu \mathrm{M}$ of each primer (Table 1). For both PCR, the amplification parameters consisted of an initial denaturation at $94^{\circ} \mathrm{C}$ for $4 \mathrm{~min}$; 30 cycles of denaturation at $94^{\circ} \mathrm{C}$ for $50 \mathrm{~s}$, annealing at $60^{\circ} \mathrm{C}$ for $50 \mathrm{~s}$, and extension at $72^{\circ} \mathrm{C}$ for $50 \mathrm{~s}$, and a final extension at $72^{\circ} \mathrm{C}$ for $6 \mathrm{~min}$. For the hemi-nested PCR, $2 \mu \mathrm{L}$ primary product was added to $18 \mu \mathrm{L}$ freshly prepared mix, as above. The amplified product was subjected to $2 \%$ agarose gel electrophoresis using 100-bp DNA ladder (Invitrogen) as a reference for fragment size and stained with ethidium bromide. In order to produce visible amplicons, the second round of PCR was not necessary for bita-actin gene.

\begin{tabular}{|c|c|c|c|c|}
\hline Gene & $\begin{array}{l}\text { Nested PCR } \\
\text { step }\end{array}$ & Nucleotide sequence & $\begin{array}{c}\text { GenBank } \\
\text { accession No. }\end{array}$ & $\begin{array}{l}\text { Product size } \\
\text { (bp) }\end{array}$ \\
\hline \multirow[t]{2}{*}{ CD44 } & $1^{\text {st }} \mathrm{PCR}$ & $\begin{array}{l}\text { 5-CAACACCTCCCASTATGACAC- } \\
3 \\
\text { 5-TTCTTCTGCCСАСАССТTCT-3 }\end{array}$ & $\begin{array}{c}\text { NM_001001391 } \\
\text { EE765662 }\end{array}$ & 570 \\
\hline & $2^{\text {nd }} P C R$ & $\begin{array}{l}\text { 5-TGGCTGATCATCATCTTGGCA- } \\
3 \\
\text { 5-TTCTTCTGCCСАСАССТTCT-3 }\end{array}$ & $\begin{array}{l}\text { EE765662 } \\
\text { EE765662 }\end{array}$ & $\begin{array}{c}92 \\
662 \\
\end{array}$ \\
\hline b-actin & $1^{\text {st }} \mathrm{PCR}$ & $\begin{array}{l}\text { 5-CAACTGGGACGACATGGA-3 } \\
\text { 5-TGGTGGTGAAGCTGTAGC-3 }\end{array}$ & $\begin{array}{l}\text { NM_001009784 } \\
\text { NM_001009784 } \\
\end{array}$ & 377 \\
\hline
\end{tabular}

The primer was designed with multiple alignments of Homo sapiens (NM 001001391), Bos Taurus (NM_174013), Mus musculus (NM_001177787), and Rattus norvergicus (NM_012924) CD44 genes. Product size expected for standard CD44 in Homo sapiens.

\section{Indirect immunofluorescence}

Immature goat $(\mathrm{N}=90)$, mature oocytes $(\mathrm{N}=40)$ and embryos $(\mathrm{N}=25)$ were washed eight times in DMPBS drops and deposited on slide coated with poly-L-lysine (Polysciences Inc., Eppelheim, Germany). The structures were fixed on $4 \%$ paraformaldehyde, $\mathrm{pH}$ 7.4, in DMPBS, at $25^{\circ} \mathrm{C}$ for 20 min, permeabilized with $1 \%(\mathrm{v} / \mathrm{v})$ Triton $\mathrm{X}-100$ and then washed three times in DMPBS. The specimens were then incubated for $3 \mathrm{~h}$ at $25^{\circ} \mathrm{C}$ with anti-human CD44 monoclonal antibody, DF1485 (Visionbiosystems Novocastra, Newcastle upon Tyne, UK), diluted to 1:40 in DMPBS containing $3 \%$ bovine serum albumin (BSA). After three washings in DMPBS, oocytes and embryos were incubated in the dark for $1 \mathrm{~h}$ with anti-mouse immunoglobulin $\mathrm{G}$ (IgG) antibody conjugated with fluorescein isothiocyanate (FITC) diluted 1:100 in DMPBS containing $3 \%$ BSA. After three washings with DMPBS, the specimens were stained with Hoechst 33342 at $1 \mathrm{mg} / \mathrm{mL}$ for $15 \mathrm{~min}$, for determination of their development stage. Finally, the slides were mounted with $90 \%$ glycerol in DMPBS and examined under a microscope (Nikon Eclipse E400, Tokyo, Japan) with epifluorescence illumination, using a B-2A filter for fluorescein (excitation wave length: 450 to $490 \mathrm{~nm}$ ) and UV-2A filter for Hoechst 33342 (excitation wave length: 330 to $380 \mathrm{~nm}$ ). The images were recorded using the Nikon DS-5M-L1 system coupled to the microscope. Additionally, to exclude the possibility of false-positive fluorescence due to non-specific binding with the secondary antibody or because of paraformaldehyde-induced autofluorescence, slides were prepared with both sheep oocytes and embryos, as well as with human lymphocytes and bovine oocytes (10 structures for each group), which were treated in the same manner as described above, but omitting the primary antibody or primary and secondary antibodies respectively.

\section{RESULTS}

Grade I and II COCs were recovered from abattoirderived ovaries, providing a mean recovery of 2.5 COCs/ovary. A total of ovulations were achieved and ocytes were recovered regarding the in vivo production of mature oocytes and corresponding to a recovery rate of $77.8 \%$. Embryo donors had a total of 50 corpora lutea and 40 embryos were recovered, resulting in a recovery rate of $68.3 \%$.

Expression analysis by hemi-nested PCR detected the presence of CD44 mRNA in mature oocytes and preimplantation embryos, whereas it was absent in immature oocytes (Figure 1). Additionally, the CD44 transcripts were also detected in human lymphocytes (positive control) in both amplifications of hemi-nested PCR.

Fluorescent staining with Hoechst 33342 allowed the visualization of the germinal vesicle in immature oocytes (Figure 2, B.2 and C.2), metaphase plate and/or polar body in mature oocytes (Figure 2, D.2) as well as the approximate number of nuclei at 
the preimplantation embryos (Figure 2, E.2). In addition, this nuclear staining confirmed the majority of lymphocytes isolated from human peripheral blood (Figure 2, A.2). Moreover, images of embryos stained with Hoechst 33342 (Figure 2, E.2) were acquired in bright field (Figure 2, E.1). The images showed to be at the morula stage. A homogeneous staining was observed in mature oocytes (Figure 2, D.3) and embryos (Figure 2, E.3), where the fluorescent signal was the most intense in the first group. After removal of the baseline signal from autofluorescence, there was no FITC staining of immature oocytes of ewes (Figure 2, C.3) and cows (Figure 2, B.3). However, human lymphocytes showed an intense fluorescent staining, distributed mainly in the peripheral region (Figure 2, A.3). No structure showed fluorescence signal as result of non-specific binding of secondary antibody.

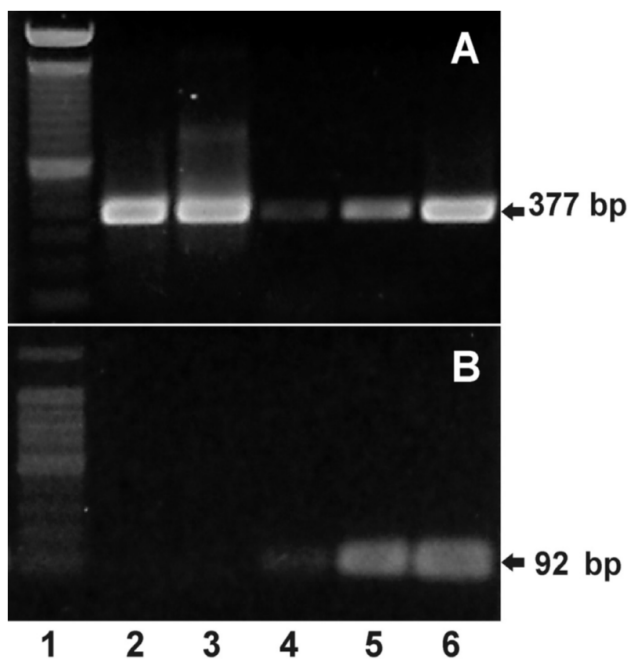

Figure 1: Detection of CD44 receptor by hemi-nested PCR amplifications in goat oocytes and embryos. Electrophoretic analysis of the b-actin (A) and CD44 (B) amplicons produced using cumulus cells of immature cumulus-oocyte complexes (lane 2), immature oocytes (lane 3), mature oocytes (lane 4), Before replacing embryos (lane 5), and human lymphocytes (lane 6) cDNA as template. Lane $1=100$-bp DNA ladder.

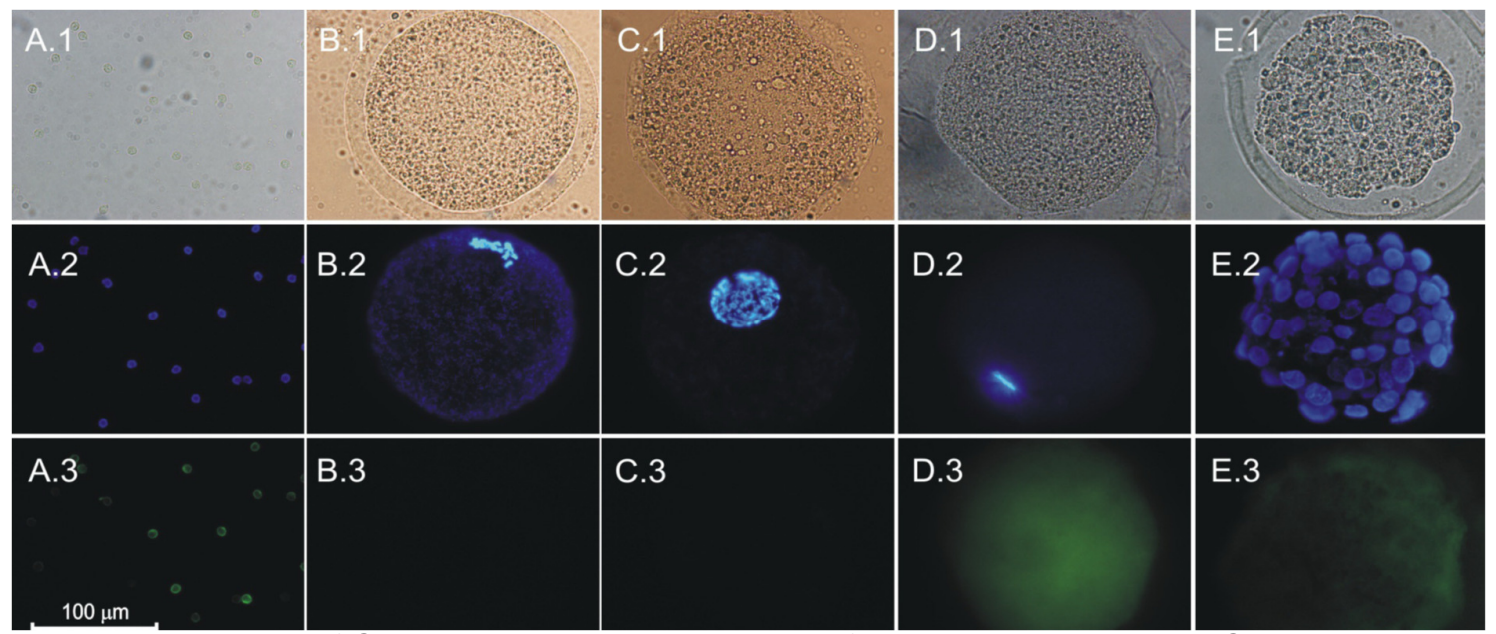

Figure 2: Detection of CD44 receptor by indirect immunofluorescence staining (FITC) in goat oocytes and embryos. Columns show human lymphocytes (positive control, A.1 to A.3), immature bovine oocyte (negative control, B.1 to B.3), immature (C.1 to C.3) and mature goat oocytes (D.1 to D.3) and sheep compact morula (E.1 to E.3). Photographs of representative structures in bright field (A.1 to E.1), epifluorescence for Hoechst 33342 (A.2 to E.2) and FITC (A.3 to E.3). 


\section{DISCUSSION}

In the present study, for the first time to our knowledge, we demonstrated that CD44 is expressed on goat mature oocytes and embryos. Using heminested PCR and indirect immunofluorescence, it was detected the expression at transcript and mature protein levels respectively. The same findings were already reported in matured oocytes in other mammalian species such as human (Campbell et al., 1995), rat (Borg and Holland, 2008), bovine (Schoenfelder and Einspanier, 2003), and porcine (Kimura et al., 2002; Yokoo et al., 2007) and in different preimplantation stages of embryos in bovine (Furnus et al., 2003), porcine (Toyokawa et al., 2005) and human (Campbell et al., 1995).

On the other hand, we found that neither CD44 mRNA nor transmembrane protein was detected in immature oocytes. This is coherent since immature oocytes should be in contact with surrounding granulose cells to allow nutrient passage and reach its proper development. This agrees with data previously reported for other mammalian species such as porcine (Yokoo et al., 2007), bovine (Furnus et al., 2003), mice (Fulop et al., 1997), and human (Campbell et al., 1995), who did not detect CD44 in immature oocytes.

No studies have established the role of the HA-CD44 system in oocyte maturation. However, Slevin et al. (1998) demonstrated that the degradation product of HA (3 to 10 disaccharides) induces the phosphorylation of the CD44 receptor, leading to the activation of kinase proteins, which are subsequently translocated to nucleus. This cascade is important for mitogenic signal transduction and sufficient for the induction of cell proliferation through the stimulation of proto-oncogenic transcription factors (Daum et al., 1994); furthermore, it plays a crucial role in activation and stabilization of the $\mathrm{M}$ phase promoting factor (MPF) during oocyte maturation (Inoue et al., 1998). Since the predominant component in the expanded cumulus is HA (Salustri et al., 1989), this probably explains the presence of the CD44 receptor in mature oocytes.

It is already known that CD44 has an influence on the expansion of the cumulus cells during the oocyte maturation (Yokoo et al., 2002), on fertility and quality of oocytes (Goodison et al., 1999). Since the hyaluronan-CD44 interaction is involved in the induction of meiotic resumption it was presumed that this receptor was expressed in the oocytes. However, it was demonstrated that this receptor is present only in cumulus cells, not in the oocyte. Recent studies have shown that the meiotic maturation of oocytes is also subject to regulation by the somatic compartment of the ovarian follicle. MPF activation at the onset of meiotic resumption is inhibited by intra-oocyte cAMP, which is transferred from cumulus cells via gap junctional communication within COCs. Interruption of gap junctions in the COCs, which occurs in response to the pre-ovulatory surge of gonadotropins (Schoenfelder and Einspanier, 2003; Assidi et al., 2008; Tunjung et al., 2009), leads to a drop in the intra-oocyte concentration of cAMP, followed by MPF activation and meiotic resumptions. The reduction of the intra-oocyte cAMP concentration was suppressed by the inhibition of the interaction between hyaluronan and CD44. This result supports the concept that hyaluronan-CD44 interaction is involved in the regulation of gap junctional communication and the termination of the cAMP flux from cumulus cells to oocytes (reviewed by Yokoo et al., 2010).

$\mathrm{Li}$ et al. (2008) reported that early production of HA occurs approximately $18 \mathrm{~h}$ after the onset of maturation, stimulated by the growth differentiation factor 9 (GDF9) and bone morphogenetic protein 15 (BMP15), which induce hyaluron synthase enzyme expression, responsible for synthesis of HA. Optimal expansion of cultured COCs requires the presence of substrates of HA synthesis and an expanded cumulus mass may positively influence oocyte viability (Chen et al., 1993). HA produced naturally by granulosa cells also prevent fragmentation or segmentation of oocytes in vitro (Sato et al., 1987).

CD44 also plays a role on embryo development up to blastocyst stage (Yokoo et al., 2002; Kimura et al., 2007). Furnus et al. (1998) supplemented I $\mathrm{mg} / \mathrm{mL} \mathrm{HA}$ to the culture medium and found the rate of bovine embryos that developed to the blastocyst stage higher than in medium alone. These authors reported that the incorporation of $\mathrm{HA}$ in a chemically defined medium clearly demonstrated the effect of $\mathrm{HA}$ in the improvement of blastocyst formation. This is in agreement with Miyano et al. (1994), who verified that the proportion of degenerated porcine embryos was lower in the presence than in the absence of HA. It has been suggested that HA might benefit embryo development per se or by regulating the action of factors synthesized by the embryo, acting in an autocrine way (Furnus et al., 2003).

The presence of CD44 in mature oocytes and preimplantational embryos suggests the expression profile of the $\mathrm{HA}$ during maturation and before replacing development. The findings of this study could be useful in the definition, investigation and also understanding of the physiological role of CD44 in the reproductive processes involved in the ovine species. Further studies are necessary to clarify the events in which CD44 and HA are involved during maturation and preimplantational embryo development in goat.

\section{REFERENCES}

Allworth AE; Albertini DF (1993). Meiotic maturation in cultured bovine oocytes is accompanied by remodeling of the cumulus cell cytoskeleton. Developmental biology. 158: 101-112.

Archibong AE, Petters RM; Johnson BH (1989). Development of porcine embryos from one- and two-cell stages to blastocysts in culture medium supplemented with porcine oviductal fluid. Biology of reproduction. 41: 1076-1083.

Assidi M, Dufort I, Ali A, Hamel M (2008). Identification of potential markers of oocyte competence expressed in bovine cumulus cells matured with follicle-stimulating hormone and/or phorbol 
myristate acetate in vitro. Biology of reproduction. 79: 209-222.

Borg N ; Holland M (2008). The effect of glycosaminoglycans on rat gametes in vitro and the associated signal pathway. Reproduction 135: 311-319.

Campbell S, Swann HR, Aplin JD, Seif MW, et al. (1995). CD44 is expressed throughout preimplantation human embryo development. Human Reproduction. 10: 425-430.

Chen L, Russell PT; Larsen WJ (1993). Functional significance of cumulus expansion in the mouse: roles for the preovulatory synthesis of hyaluronic acid within the cumulus mass. Molecular reproduction. 34: 87-93.

Daum G, Eisenmann-Tappe I, Fries HW, Troppmair J (1994). The ins and outs of Raf kinases. Trends in biochemical. 19: 474-480.

Fulop C, Salustri A ; Hascall VC (1997). Coding sequence of a hyaluronan synthase homologue expressed during expansion of the mouse cumulus-0ocyte complex. Human reproduction. 337: 261-266.

Furnus CC, de Matos DG ; Martinez AG (1998). Effect of hyaluronic acid on development of in vitro produced bovine embryos. Theriogenology. 49: 1489-1499.

Furnus CC, Valcarcel A, Dulout FN ; Errecalde AL (2003). The hyaluronic acid receptor (CD44) is expressed in bovine oocytes and early stage embryos. Theriogenology. 60: 1633-1644.

Goodison S, Urquidi V ; Tarin D (1999). CD44 cell adhesion molecules. Molecular Pathology. 52: 189-196.

Inoue M, Naito K, Nakayama T and Sato E (1998). Mitogen-activated protein kinase translocates into the germinal vesicle and induces germinal vesicle breakdown in porcine oocytes. Biology of reproduction. 58: 130-136.

Jackson RL, Busch SJ ; Cardin AD (1991). Glycosaminoglycans: molecular properties, protein interactions, and role in physiological processes. cellular physiology. 71: 481-539.

Kaya G, Laurini R, Chaubert P ; Gross N (2001). Expression of CD44 and its isoforms in the fetal neuroblasts.. Morpholgy. 9: 180-184.

Kimura N, Konno Y, Miyoshi K, Matsumoto H, et al. (2002). Expression of hyaluronan synthases and CD44 messenger RNAs in porcine cumulus-oocyte complexes during in vitro maturation. Biology Reported. 66: 707-717.

Kimura N, Hoshino Y, Totsukawa K ; Sato E (2007). Cellular and molecular events during oocyte maturation in mammals: molecules of cumulusoocyte complex matrix and signalling pathways regulating meiotic progression. Society of Reproduction. 63: 327-342.

Lee CN ; Ax RL (1984). Concentrations and composition of glycosaminoglycans in the female bovine reproductive tract. J. Dairy Sci. 67: 20062009.

Li HK, Kuo TY, Yang HS, Chen LR, et al. (2008). Differential gene expression of bone morphogenetic protein 15 and growth differentiation factor 9 during in vitro maturation of porcine oocytes and early embryos. Animal reproduction. 103: 312-322.

Miyano T, Hiro-Oka RE, Kano K, Miyake M, (1994). Effects of hyaluronic acid on the development of 1and 2-cell porcine embryos to the blastocyst stage in vitro. Theriogenology. 41: 1299-1305.

Ohta N, Saito H, Kaneko T, Yoshida M (2001). Soluble CD44 in human ovarian follicular fluid. J Assist. assisted reproduction. 18: 21-25.

Peterson PE, Pow CS, Wilson DB ; Hendrickx AG (1993). Distribution of extracellular matrix components during early embryonic development in the macaque. Cells Tissues. 146: 3-13.

Salustri A, Yanagishita M ; Hascall VC (1989). Synthesis and accumulation of hyaluronic acid and proteoglycans in the mouse cumulus cell-oocyte complex during follicle-stimulating hormoneinduced mucification. biology Chemictry. 264: 13840-13847.

Salustri A, Ulisse S, Yanagishita $M$; Hascall VC (1990). Hyaluronic acid synthesis by mural granulosa cells and cumulus cells in vitro is selectively stimulated by a factor produced by oocytes and by transforming growth factor-b. biology Chemictry. 265: 19517-19523.

Sato E, Ishibashi T and Koide SS (1987). Prevention of spontaneous degeneration of mouse oocytes in culture by ovarian glycosaminoglycans. Biology Reported. 37: 371-376.

Sato E, Inoue M, Takahashi Y ; Toyoda Y (1994). Glycosaminoglycans prevent induction of fragmentation of porcine oocytes stimulated by dibutyryl cyclic adenosine $3^{\prime}, 5^{\prime}$-monophosphate in culture. Cell structure and function. 19: 29-36.

Schoenfelder M ; Einspanier R (2003). Expression of hyaluronan synthases and corresponding hyaluronan receptors is differentially regulated during oocyte maturation in cattle. Biolog Reported. 69: 269-277.

Slevin M, Krupinski J, Kumar S ; Gaffney J (1998). Angiogenic oligosaccharides of hyaluronan induce protein tyrosine kinase activity in endothelial cells and activate a cytoplasmic signal transduction pathway resulting in proliferation. Laboratory investigation. 78: 987-1003.

Toyokawa K, Harayama H ; Miyake M (2005). Exogenous hyaluronic acid enhances porcine parthenogenetic embryo development in vitro possibly mediated by CD44. Theriogenology. 64: 378-392.

Tunjung WA, Yokoo M, Hoshino Y, Miyake Y (2009). Effect of hyaluronan to inhibit caspase activation in porcine granulosa cells. Biochemical and Biophysical Research Communications. 382: 160164.

Wheatley SC, Isacke CM ; Crossley PH (1993). Restricted expression of the hyaluronan receptor, CD44, during postimplantation mouse embryogenesis suggests key roles in tissue formation and patterning. Development. 119: 295306.

Yokoo M, Miyahayashi Y, Naganuma T, Kimura N, et al. (2002). Identification of hyaluronic acid-binding 
proteins and their expressions in porcine cumulusoocyte complexes during in vitro maturation. Biology Reported. 67: 1165-1171.

Yokoo M, Shimizu T, Kimura N, Tunjung WA, et al. (2007). Role of the hyaluronan receptor CD44 during porcine oocyte maturation. Reproduction in Domestic Animals. 53: 263-270.
Yokoo M, Kimura N ; Sato E (2010). Induction of oocyte maturation by hyaluronan-CD44 interaction in pigs. J. Reproduction in Domestic Animals. Dev. 56: 15-19.

\footnotetext{
Cite this Article: Aminafshar M, Bahrampour V, Bagizadeh A, Kashan NEJ and Abadi MRM, 2014. Expression of CD44 Gene in Goat's Oocytes and Embryos. Greener Journal of Biological Sciences, 4 (5), 139-145, http://doi.org/10.15580/GJBS.2014.5.050614223.
} 